\title{
Analysis on Marketing Strategies From the View of Enterprise Life Cycle
}

\author{
Jian Zhou \\ Jiangxi Vocational College of Finance and Economics, Jiujiang, 332000, China
}

Keywords: Enterprise life cycle. Marketing strategies. Enterprise development.

\begin{abstract}
For most enterprises, marketing is one of the most important channels to gain benefits. Moreover, it is the fundamental guarantee for them to promote the health, stable and sustainable development of enterprises. A reasonable and feasible marketing strategy can provide enterprises with huge profits. Enterprises have to experience different stages during their life cycle. Berceuse the problems faced by them in every stage are different, different marketing strategies should be made for different stages in the life cycle. Therefore, enterprises' marketing strategies are analyzed from the view of their life cycle in this paper.
\end{abstract}

\section{Theoretical review on enterprise life cycle and enterprise marketing strategies}

\section{Enterprise life cycle}

A life cycle of people is the time from the person's birth to his death. During this period, the person experiences several different development stages as infant, juvenile, youth, middle age and old age. The end point of all the stages is death. The life cycle of human has a very typical characteristic, that is, irreversibility. The concept of enterprise life cycle was firstly put forward by Mason Haire. The thought we can recognize enterprises with the concept of human's life cycle. Moreover, the development of enterprises is in line with the law of growth in biology. Gardner pointed out that enterprises are like human or any other creatures. They have life cycles as well. However, enterprise life cycle must have some typical characteristics, which are reflected in the unpredictable feature in the development of enterprises, the lag stage in the development of enterprises and irreversible demise of enterprises. Ichak Adizes is one of the most representative figures in enterprise life cycle theory. He divided the whole development of enterprises into ten stages as incubation stage, infant stage, go-go stage, adolescence, prime stage, aristocracy stage, beginning stage of bureaucracy, bureaucracy stage and death stage. Domestic scholars modified and improved the researches of western scholars. For instance, Chen Jiaze re-divided the life cycle of enterprise, that is, incubation stage, survival stage, rapid development stage, mature period, decline stage and metamorphosis stage. He held that when an enterprise steps into the decline stage, it does not mean that it is doomed to perish. Instead, it can enter into another new life cycle through metamorphosis. This concept is very meaningful for the sustainable development of enterprises.

\section{Enterprise' marketing strategies}

Enterprise marketing is also called as marketing management, which is one important part of enterprise management. Specifically, it means the operations and strategies (such as price strategy and promotion strategy, etc.) that are beneficial to the marketing of the products that was made by the enterprises organically and designedly to provide customers with satisfied products and services according to the judgments of customers' demands and purchasing power as well as their expectations on the enterprises' products based on their previous experiences by taking customers as the core. The final objective of marketing is to win larger market share, improve the competitiveness of the emprises in market and promote the health, stable and sustainable development of enterprises through creating more customers. Generally, the marketing strategies of enterprises can be divided into three steps: market segmentation, target marketing and accurate positioning for market. 


\section{Analysis on the relation between enterprise life cycle and enterprise marketing}

\section{Complementary relation}

For an enterprise, it is better to have a longer life cycle. However, how to maximize the life cycle of enterprises? It is a subject worthy of in-depth discussion. Through continuous researches, it is found that the reasonable and feasible marketing strategies of enterprises can bring enterprises with large economic benefits, so as to promote the health and sustainable development of enterprises. In this way, the life cycle of the enterprises can be prolonged continuously. On the contrary, the continuous extension of life cycle of enterprises reflects that the marketing strategies of these enterprises are with high feasibility and rationality, based on which, enterprises can make the subsequent marketing strategies to form a virtuous circle. In this way, there is a commentary relation between the life cycle and marketing strategies of enterprises.

\section{Interactive relation}

There is a very obvious interactive relation between enterprise marketing strategies and their life cycle. It is reflected in the following aspects: first, after overall and systematic investigation and analysis, enterprises set up scientific and reasonable marketing strategies and ensure that these strategies should be in line with the conditions of each development stages of enterprises, so as to promote the development of these enterprises effectively and enable the enterprises to transit to the next stage smoothly. In other words, scientific and reasonable enterprise marketing strategies can impact positive promoting influences on the development of the enterprises. If enterprises did not carry out overall and systematic investigation and analysis before they set up their marketing strategies, they are likely to face with many mistakes in decisions. In this way, the marketing strategies can not promote the development of the enterprises. Moreover, they are likely to bring these enterprises with devastating damages. As a result, these enterprises go to extinction quickly. Second, the continuous good development of enterprise life cycle is an affirmation for the marketing strategies of the enterprise. It proves that the current marketing strategies of the enterprise are correct, reasonable and feasible. If there are any setbacks and deformed development in the life cycle of the enterprise, it means that the marketing strategies of the enterprise may be unreasonable or infeasible, which can impact certain influences on the establishment of the subsequent marketing strategies of the enterprise. Moreover, it can affect the life cycle of the enterprise indirectly.

\section{Research on the marketing strategies based on the life cycle of enterprise}

Through the context, we can know that experts and scholars from both home and abroad have divided the life cycle of enterprise in details. Considering the main direction of this paper is marketing, the life cycle of enterprise is re-divided into five stages based on the existing theoretical basis: initial stage, growth stage, mature stage, decline stage and transformation stage. In this way, the research can be carried out conveniently. Then, the marketing strategies for the five stages are researched.

\section{Marketing strategies in the initial stage of enterprise}

The initial stage of enterprise refers to the period that the enterprise is just founded. During this stage, the scale of the enterprise is not large and the comprehensive strength of it is relatively weak and the fund of the enterprise is relatively less. These factors can limit the rapid development of the enterprise to certain extents. Through all the risks during this stage are shouldered by the entrepreneur, the operations in the enterprise are relatively flexible. The market can be opened with some special technologies and products to accumulate wealth. During this stage, enterprises can adopt the following marketing strategies:

\section{Market concentration strategy}

Enterprises in initial stage should fully understand their advantages and choose a region with an initial market scale as the target market and then plan the marketing strategies by combining the characteristics of the region and the characteristics of the products of the enterprise. Some feasible and effective marketing methods should be used to open the market. When choosing market, 
enterprises should try their best to find out the neglected or unsatisfied layers and devote themselves to them to gather special competences within the shortest time to expand gradually.

\section{Optimization of product}

Generally, it is difficult for enterprises to let customers accept their products during their initial stage. If unsalable phenomenon occurs to their products during the initial stage, the development of enterprises will be certainly influenced significantly. Therefore, enterprises should optimize their products continuously. They should improve their products from both the quality and performance. Moreover, they should try to reduce the cost of their products and price their products based on the principle of less profit. Meanwhile, the can put their products in the market segment where the similar products are popular to meet the practical demands of customers and gain the acceptance of customers within the shortest time. It is very helpful to improve the sales of the products.

\section{Promotion strategy}

If the products can not open the market rapidly, the strength of advertising and promotion should be strengthened to attract more attentions from customers and expand the market influences of the products, so as to improve the popularity of the products.

\section{Marketing strategies during growth stage}

With the continuous efforts during the initial stage, enterprises tried their best to win the acceptance and approval of customers for their products. Therefore, they win certain shares in market. Meanwhile, they accumulate certain amount of funds. At that time, the enterprise steps into the growth stage gradually. In this stage, the scale of the enterprise is expanded gradually and the management and operation personnel become more and the organizational structure become more complex.

\section{Establish diversified marketing channels}

Through the establishment of diversified marketing channels, enterprises can avoid various risks caused by single market, which is conducive to ensuring the safety of the operations of enterprises. When applying this marketing strategy, enterprises should carry out sufficient investigations in advance to analyze the market comprehensively and systematically. Moreover, they should compile reasonable and feasible manufacturing plans and supply channel plans according to their analysis results, which is conducive to expanding the selling channels of the products.

\section{Applying brand strategy reasonably}

With the continuous improvement of people's knowledge, customers' cognition degree for brands is higher and higher. Therefore, a great many of many customers choose products according to brands. For the enterprise in growth stage, they should pay enough attention to the establishment of brand. They can expand their publicity further and popularize their products through network media to establish distinctive brand images in customers, so as to gain customers approval in their products and strengthen their loyalty, which is conducive to promoting the development of those enterprises. In addition, when carry out marketing activities, marketing personnel of the enterprises can establish one brand or several brands at the same time to win more market shares for their products and make greater values for their enterprises.

\section{Marketing strategies in mature stage}

For enterprises, mature stage is the golden stage for product distribution. During this stage, enterprises should not be satisfied with the current interests. Instead, they should be enterprising enough to take active and aggressive marketing strategies to strive for stable market shares, which is conducive to prolonging the market life of their products and further prolonging the life cycle of themselves. During mature stage, enterprises can take comprehensive marketing strategies to take up market. For instance, enterprises should look at the whole market. They should realize the comprehensive expansion through taking up the corresponding market with different products. In this way, enterprises can take the leading place in their industries for a long time. Generally, when enterprises step into the mature stage, they are endowed with solid economic foundation and strong technical power. Then, they can attract customers' attention through price advantages and product innovations. Therefore, they can invade and take up new markets. 


\section{Marketing strategies in decline stage}

When enterprises are affected by various factors, it is very easy for them to enter into the decline stage. In this stage, if enterprises do not handle with problems well, they are very likely to decline and perish. Therefore, this stage is very important for enterprises. They should make targeted marketing strategies in this stage. They should emphasize innovative marketing. They should carry out new market investigations, find out new demands of customers and reposition their development goals. Meanwhile, they should give up the markets that are not beneficial for their development, improve the standards of their core businesses and reconstruct their industrial chains.

\section{Marketing strategies in revolution stage}

This stage can be seen as the extension of decline stage. If enterprises can realize development again in this stage, they can get a fresh start in another life cycle. There are relatively more marketing strategies in this stage to be chosen by enterprises, such as developing new products, improving 2nd generation products, transforming the previous marketing strategies and eliminating the products without competitiveness in markets, etc. Though the natures of these strategies are different, their final goal is the same, that is, reviving the enterprises and pushing them into another new life cycle through marketing strategies.

\section{Conclusion}

All in all, in the market-oriented economy, domestic enterprises have to put economic benefits at the first place to survive and develop in the fierce competitions. Among the various channels through which enterprises gain economic benefits, marketing is, without doubt, the most effective one. Moreover, it is the foundation for the survival and development of enterprises. Therefore, enterprises should establish reasonable and scientific marketing strategies to gain more customers and obtain larger market shares. Only in this way, they can remain invincible in the fierce market competitions, maintain sustainable development and further prolong the life cycle of themselves.

\section{References}

[1] Cao Chongyan, Ren Jie and Xu Chongchun: Free Cash Flow and Inefficient Investment: Empirical Research Based on Enterprise Life Cycle, Luojia Management Review, 2012 (12).

[2] Yuan Xiong and Deng Zehong: Construction of the Ideal Model of Enterprise Social Responsibility: Based on the Enterprise Life Cycle Theory, Contemporary Economics, 2013 (9).

[3] Cao Yu, Chen Xiaohong and Li Xihua: Research on the Relation Between Intellectual Capital and Enterprise Performance Based on Enterprise Life Cycle, Chinese Academy of Management Annual Conference -Collected Papers of Management Science and Engineering [C], 2009 (11).

[4] Wu Zengguo and Li Fuxue: Research on Enterprise Life Cycle and Marketing Strategies-Taking Mengniu Dairy as an Example, Modern Enterprise Education, 2010 (8).

[5] Chen Xiaodan: Research on the Value Evaluation Method of Listed Company From the View of Life Cycle [D], Southwestern University of Finance and Economics, 2010 (9).

[6] Mu Nanzhu: Research on the Selection of Enterprise Competition Strategies Based on Enterprise Life Cycle and Industry Life Cycle [D], Sichuan University, 2010 (5).

[7] Shen Weiling and Chen Jinyang: Analysis on Enterprise Marketing Strategies --- Based on the Product Life Cycle Theory, Contemporary Economics (the latter half), 2011 (8). 